\title{
Clinical diagnosis of hyposalivation in hospitalized patients
}

\author{
Soraya de Azambuja BERTI-COUTO ${ }^{1}$, Paulo Henrique COUTO-SOUZA², Reinhilde JACOBS ${ }^{3}$, Olivia NACKAERTS ${ }^{4}$, \\ Izabel Regina Fischer RUBIRA-BULLEN ${ }^{5}$, Fernando Henrique WESTPHALEN², Samuel Jorge MOYSÉS², Sérgio \\ Aparecido IGNÁCIO ${ }^{6}$, Maitê Barroso da COSTA ${ }^{1}$, Ana Lúcia TOLAZZI ${ }^{7}$
}

\author{
1- DDS, MSc, School of Dentistry, Pontifical Catholic University of Paraná, Curitiba, PR, Brazil. \\ 2- DDS, MSc, PhD, Full Professor, School of Dentistry, Pontifical Catholic University of Paraná, Curitiba, PR, Brazil. \\ 3- DDS, MSc, PhD, Oral Imaging Center, Faculty of Medicine, Catholic University of Leuven, Leuven, Belgium. \\ 4- MSc, PhD, Oral Imaging Center, Faculty of Medicine, Catholic University of Leuven, Leuven, Belgium. \\ 5- DDS, MSc, PhD, Associate Professor, Department of Stomatology, Bauru School of Dentistry, University of São Paulo, Bauru, SP, Brazil. \\ 6- MSc, PhD, Full Professor, School of Dentistry, Pontifical Catholic University of Paraná, Curitiba, PR, Brazil. \\ 7- DDS, MSc, PhD, Assistant Professor, School of Dentistry, Pontifical Catholic University of Paraná, Curitiba, PR, Brazil.
}

Corresponding address: Prof. Paulo Henrique Couto Souza - Pontifícia Universidade Católica do Paraná - Escola de Saúde e Biociências, Curso de Odontologia, Rua Imaculada Conceição, 1155 - Prado Velho - 80215-901 - Curitiba - Paraná - Brazil - Phone/Fax: 55413271 -1637 / 55413271 -1405 - e-mail: couto.s@pucpr.br/souzaphc@yahoo.com.br

Received: April 09, 2010 - Modification: June 21, 2010 - Accepted: January 27, 2011

\section{ABSTRACT}

\begin{abstract}
$\mathrm{O}$ bjective: The aim of this study was to evaluate the effectiveness of clinical criteria for the diagnosis of hyposalivation in hospitalized patients. Material and Methods: A clinical study was carried out on 145 subjects (48 males; 97 females; aged 20 to 90 years). Each subject was clinically examined, in the morning and in the afternoon, along 1 day. A focused anamnesis allowed identifying symptoms of hyposalivation, like xerostomia complaints (considered as a reference symptom), chewing difficulty, dysphagia and increased frequency of liquid intake. Afterwards, dryness of the mucosa of the cheecks and floor of the mouth, as well as salivary secretion during parotid gland stimulation were assessed during oral examination. Results: Results obtained with Chi-square tests showed that 71 patients $(48.9 \%)$ presented xerostomia complaints, with a significant correlation with all hyposalivation symptoms $(p<0.05)$. Furthermore, xerostomia was also significantly correlated with all data obtained during oral examination in both periods of evaluation $(p<0.05)$. Conclusion: Clinical diagnosis of hyposalivation in hospitalized patients is feasible and can provide an immediate and appropriate therapy avoiding further problems and improving their quality of life.
\end{abstract}

Key words: Hyposalivation. Xerostomia. Saliva. Hospital.

\section{INTRODUCTION}

Hyposalivation is the reduction of salivary flow and can be assessed by specific exams, such as sialometry method ${ }^{12,15}$, while xerostomia is rather a subjective feeling of oral dryness. The latter is however not necessarily related to a reduction of salivary flow, because this symptom has also been reported by patients who did not present with hyposalivation ${ }^{6,7,9,13,16,17}$. The etiology is associated with drugs that inhibit salivary flow, like psychotropics, with autoimmune diseases, like Sjögren's Syndrome, and with head and neck radiation therapy $1,11,15,17,21$. Moreover, chronic anxiety, depression, hemodialysis, diabetes mellitus and dehydration can also be associated $6,7,29$. The reduction of salivary flow may also induce oral mucosa infection like Candida spp. and, furthermore, increases the number of dental caries ${ }^{4,25}$.

During anamnesis and oral examination, some symptoms and signals are strongly correlated to hyposalivation. Symptoms include a burning feeling of the tongue, dysphonia, an increase in the frequency of liquid intake and dysphagia15,20,22. Signals are the presence of small amounts of frothy, thick or sticking saliva, fissuring and atrophy of the filiform papillae, erythematous mucosal areas, halitosis and oral mucosal dryness ${ }^{21}$. 
As a consequence, clinical diagnosis of hyposalivation can be obtained only with the patient's history and oral examination ${ }^{12}$. In addition, other complementary methods like sialometry, sialochemistry and sialography are accurate for the diagnosis of hyposalivation ${ }^{3,18}$. However, these methods are difficult to carry out in hospitalized patients considering their physical limitations. Furthermore, some studies have found that only clinical examinations, including subjective reports, can be highly indicative of hyposalivation without any complementary method ${ }^{16}$.

The majority of hospitalized patients have physical limitations and systemic diseases justifying the use of several drugs. Most of such drugs are associated with the emergence and/or worsening of hyposalivation, as such that simple and rapid clinical diagnosis of this condition becomes essential. Yet, hardly any study has dealt with the development of a simple clinical diagnostic tool to simply and reliably detect cases of hyposalivation in a hospitalized population. Therefore, this study aimed to evaluate the effectiveness of clinical criteria that are strongly correlated to the diagnosis of hyposalivation in hospitalized patients.

\section{MATERIAL AND METHODS}

This study was approved by the Research Ethics Committee of the School of Dentistry, Pontifical Catholic University of Paraná (PUCPR), Brazil.

The initial population consisted of 221 hospitalized patients, aged 20 to 90 years, admitted to two university hospitals from Curitiba, PR, Brazil, due to several medical reasons, between February and May 2008. All patients have been hospitalized for

Does your mouth feel dry?

Do you experience any difficulties chewing dry foods?

Do you experience any difficulties swallowing dry foods?

Are you aware of any recent increase in the frequency of liquid intake?

Figure 1- Anamnesis focused on hyposalivation at least 10 days. Exclusion criteria included salivary gland removal, head and neck radiation therapy, cholinergic drug intake and cognitive deficit, like Alzheimer's disease in an advanced stage. The final sample consisted of 145 patients, 48 males and 97 females (mean age $54.1 \pm 15.7$ years, range: $21-88$ years). Each patient was examined in the morning and in the afternoon, during only 1 day.

Clinical assessment including anamnesis and oral examination was performed by a single observer. First, xerostomia complaints, considered as potential reference symptoms, were recorded followed by evaluation of chewing and dysphagia difficulties of dry foods and the increase in the frequency of liquid intake through anamnesis (Figure 1). Afterwards, cheek mucosa dryness was evaluated by visual inspection, palpation and adherence degree of mucosal surface using a wooden spatula. The presence of a saliva pool accumulated on the floor of the mouth and salivary secretion during extraoral parotid glands stimulation by the palpation method, were assessed by oral inspection. All clinical information was obtained and adapted according to the data in previous studies $8,11,13,16,18,19,21,24$. Clinical assessment was carried out between 09:00 and 11:30 (morning) and between 1:30 and 3:00 (afternoon), considering the potential influence of the circadian cycle on the patients' saliva production ${ }^{5}$. Information concerning the symptoms of xerostomia, chewing, dysphagia and the increasing of liquid intake was obtained only in the morning.

Data were analyzed using Chi-square tests with a significance level of $5 \%$. Thus, the relation amongst all variables could be examined.

\section{RESULTS}

Table 1 shows the results of patients who presented symptoms associated with hyposalivation. Results showed that from 145 patients, 71 (48.9\%) presented with xerostomia complaints. From these 71 patients, $30(42.3 \%)$ presented with difficulties during chewing, 30 (42.3\%) during swallowing, while $48(67.6 \%)$ reported an increase in the frequency of liquid intake.

Table 1- Relation between xerostomia complaint and chewing difficulty, dysphagia and increased frequency of liquid intake

\begin{tabular}{cccc}
\hline $\begin{array}{c}\text { Reference symptom } \\
\text { Associated symptoms }\end{array}$ & $\begin{array}{c}\text { Xerostomia complaint } \\
\text { Presence } \\
\text { (71 patients) }\end{array}$ & $\begin{array}{c}\text { Absence } \\
\text { (74 patients) }\end{array}$ & p value \\
\hline Chewing difficulty & $30(42.3 \%)$ & $4(5.4 \%)$ & 0.00 \\
Dysphagia & $30(42.3 \%)$ & $6(8.1 \%)$ & 0.00 \\
Increased frequency of liquid intake & $48(67.6 \%)$ & $10(13.5 \%)$ & 0.00 \\
\hline
\end{tabular}

Note: Value of $p<0.05$ shows statistical correlation among the variables 
Table 2- Relation between xerostomia complaint and total number of patients with mucosa of the cheeks dryness in the morning and in the afternoon

\begin{tabular}{cccc}
\hline $\begin{array}{c}\text { Xerostomia complaint } \\
\text { Mucosa of the cheeks dryness }\end{array}$ & $\begin{array}{c}\text { Presence } \\
\text { (71 patients) }\end{array}$ & $\begin{array}{c}\text { Absence } \\
\text { (74 patients) }\end{array}$ & p value \\
\hline Morning & $36(50.7 \%)$ & $22(29.7 \%)$ & 0.01 \\
Afternoon & $29(40.8 \%)$ & $15(20.3 \%)$ & 0.01 \\
\hline
\end{tabular}

Note: Value of $p<0.05$ shows statistical correlation among the variables

Table 3- Relation between xerostomia complaint and total number of patients with floor of the mouth dryness

\begin{tabular}{cccc}
\hline $\begin{array}{c}\text { Xerostomia complaint } \\
\text { Floor of the mouth dryness }\end{array}$ & $\begin{array}{c}\text { Presence } \\
\text { (71 patients) }\end{array}$ & $\begin{array}{c}\text { Absence } \\
\text { (74 patients) }\end{array}$ & p value \\
\hline Morning & $47(66.2 \%)$ & $22(29.7 \%)$ & 0.00 \\
Afternoon & $39(54.9 \%)$ & $15(20.2 \%)$ & 0.00 \\
\hline
\end{tabular}

Note: Value of $p<0.05$ shows statistical correlation among the variables

Table 4- Relation between xerostomia complaint and total number of patients without salivary secretion during parotid glands stimulation

\begin{tabular}{cccc}
\hline $\begin{array}{c}\text { Xerostomia complaint } \\
\text { Parotid gland stimulation }\end{array}$ & $\begin{array}{c}\text { Presence } \\
\text { (71 patients) }\end{array}$ & $\begin{array}{c}\text { Absence } \\
\text { (74 patients) }\end{array}$ & p value \\
\hline Morning & $44(62 \%)$ & $24(34.7 \%)$ & 0.00 \\
Afternoon & $29(40.8 \%)$ & $15(20.3 \%)$ & 0.01 \\
\hline
\end{tabular}

Note: Value of $p<0.05$ shows statistical correlation among the variables

Tables 2, 3 and 4 show the results of patients who presented mucosa of the cheeks and floor of the mouth dryness and absence of salivary secretion during parotid glands stimulation, respectively. Data obtained in the morning and in the afternoon, are presented separately in these tables. These findings showed that there was statistically significant correlation among the variables $(p<0.05)$.

\section{DISCUSSION}

The present study showed that almost half of the total sample $(n=71)$ (Table 1$)$, presented with clinical signs and symptoms of xerostomia. Despite the fact that this symptom is not considered determinant of hyposalivation, xerostomia symptoms present subjective complaints of hospitalized patients that should be diagnosed timely. Previous studies 2,26 confirm that hyposalivation is one of the most frequent problem amongst those patients. In the same way, some authors have reported that during anamnesis, simple questions regarding xerostomia might be useful as a reliable predictor of hyposalivation ${ }^{2,11}$. Glazar, et al. ${ }^{10}$ (2010) evaluated the prevalence of dry mouth and taste disturbance, salivary flow rate and oral mucosal lesions in institutionalized and non-institutionalized elderly and concluded that the institutionalized population is significantly more affected by dry mouth and taste disturbance complaints, decreased salivary flow rate and oral mucosal diseases when compared with the other group. Although xerostomia is considered as a subjective complaint, the present study applied it as a reference symptom, considering its clinical relevance for hospitalized medically compromised patients. Usually, such patients do not drink, eat, or even speak and the quality of life during the hospitalization period becomes worse daily. In fact, the present results showed that xerostomia had a significant correlation with chewing and swallowing difficulties and with an increase in the frequency of liquid intake confirming the results from previous studies ${ }^{15,16}$. Similarly, Fox, et al. ${ }^{9}$ (1987) considered the xerostomia subjective complaint as a valuable tool to identify patients who require additional salivary gland evaluation. This aspect becomes more important in hospitalized patients because, most often, they are taking several systemic drugs whose side effects can compromise the function of salivary glands.

The fact of xerostomia is considered a subjective symptom was clearly observed in the current study. Tables 1-4 show that patients who did not have xerostomia complaint, also presented its classical 
signals and symptoms, for instance, chewing difficulty $(5.4 \%)$, dysphagia $(8.1 \%)$, increased frequency of liquid intake $(13.5 \%)$, cheek mucosa dryness (29.7\% and $20.3 \%)$ and floor of the mouth dryness (29.7\% and $20.2 \%)$, and parotid gland stimulation (34.7\% and $20.3 \%$ ). However, it is also possible to see in the same tables that the presence of all these classical signals and symptoms in the patients who presented with xerostomia complaint was significantly higher.

The clinical data obtained during oral examination were associated with xerostomia in the morning and in the afternoon. When this symptom was compared with cheek mucosa and floor of the mouth dryness, and with the absence of salivary secretion during parotid glands stimulation, it was observed that a significant number of patients showed these clinical signals in both measuring moments (Tables 2, 3 and 4). These results can be considered highly suggestive of hyposalivation according Longman, et al. ${ }^{16}$ (2000) and Navazesh, et al. ${ }^{18}$ (1992), especially if they are observed at the same time and in two periods of evaluation, in the morning and in the afternoon, as in the present study.

Considering that the current research is an initial study, each patient was examined in the morning and in the afternoon, during only 1 day. However, it is important to state that further researches are necessary to evaluate hyposalivation in hospitalized patients on a daily basis, as each patient might be examined during the entire period of their hospitalization. Consequently, the progressive hyposalivation condition in hospitalized patients could be better understood.

Dawes $^{5}$ (1975) carried out a study regarding the influence of the circadian cycle on salivary composition and salivary flow, stimulated and nonstimulated, taking into account 5 evaluations per day during 11 days in each patient. In Dawes' study, the non-stimulated saliva group showed differences in flow rate and sodium, potassium, magnesium, chloride and inorganic phosphate concentrations but not in protein and calcium. In contrast, the stimulated saliva group did not show differences only in protein concentration. In the current study, the circadian cycle did not present significant influence on the results considering the small difference of percentages between both periods (Tables 2, 3 and 4). Yet, patients were examined only twice in one day, as such that no definite conclusion regarding the circadian cycle could be presented. However, the physical limitations presented by hospitalized patients in the current study did not allow several evaluations of salivary flow per day.

Consequently, simple methods to diagnose hyposalivation, as used in the present study, could easily spot patients with this problem, as such to more effectively and immediately provide therapy like dry mouth solutions, rinses, toothpastes, salivary substitutes and avoid any further problems in already compromised patients. Several authors ${ }^{12,23,27,29}$ cited that it is very important to identify the causative agent and the appropriate therapy to hyposalivation, which includes increasing oral hydration and the use of systemic cholinergic drugs, stimulants, lubricants and more recently acupuncture. In addition to theses aspects, hyposalivation may predispose infection diseases like candidiasis, which can be more aggressive in hospitalized patients requiring special oral care ${ }^{25}$.

The clinical criteria considered in this study showed to be valuable for a simple clinical diagnosis of hyposalivation in hospitalized patients. In the hospital environment, such a simple exam could avoid more invasive and exhausting exams. On the other hand, for those patients who do not present these classical findings, oral examination could be a valuable exam that might indicate the need for other specific exams, such as sialometry, sialochemistry and sialography. Furthermore, the oral examination, including xerostomia investigation, could be at least indicative for supportive therapy, for instance the use of artificial saliva or other methods that could help salivary glands stimulation. To illustrate, Van Steenberghe, et al. $^{28}$ (1994) evaluated the effectiveness of a test toothpaste containing the lactoperoxidase system, compared to a normal fluoridated toothpaste in xerostomic patients, demonstrating the efficacy of the lactoperoxidase system administered by a toothpaste, on supragingival plaque control in those patients.

The findings of the oral examination confirm the results of a previous study ${ }^{16}$, which showed that oral mucous dryness, diagnosed by a clinical dentist, can help identifying patients with salivary flow changes, without necessitating the use of sialometry. Moreover, these clinical findings of hyposalivation aid the identification of patients who need a specific medical evaluation to diagnose possible systemic diseases such as Sjögren's Syndrome.

As far as the literature could be explored, the majority of epidemiological studies concerning hyposalivation diagnosis is carried out in outdoor patients ${ }^{13,14,20,24}$. So far, a small number of studies have been performed on medically compromised hospitalized patients ${ }^{2,10,19}$. As a consequence, studies reporting on oral clinical findings of hyposalivation in the hospital environment are necessary for a better diagnosis and treatment of this condition in hospitalized patients.

\section{CONCLUSION}

In conclusion, the results of the present study show that the clinical diagnosis of hyposalivation 
in hospitalized patients is feasible and has a great clinical relevance. Indeed, the simple and quick diagnosis may allow to immediately starting an appropriate therapy for hyposalivation, thus improving the quality of life in hospitalized patients. Furthermore, the clinical diagnostic criteria are simple and non-invasive, creating the possibility for delegation to other health professionals like the nursing staff. Further studies should attempt to address the necessity to teach health professionals, who are involved in a multidisciplinary care, how to make a feasible and reliable diagnosis of hyposalivation in hospitalized patients. The oral health of hospitalized patients should indeed be considered an important aspect contributing to the overall health of those patients.

\section{REFERENCES}

1- Astor FC, Hanft KL, Ciocon JO. Xerostomia: a prevalent condition in the elderly. Ear Nose Throat J. 1999;78:476-9.

2- Avcu N, Ozbek M, Kurtoglu D, Kurtoglu E, Kansu O, Kansu H. Oral findings and health status among hospitalized patients with physical disabilities, aged 60 or above. Arch Gerontol Geriatr. 2005; 41:69-79.

3- Cassolato SF, Turnbull RS. Xerostomia: clinical aspects and treatment. Gerodontology. 2003;20:64-77.

4- Cho MA, Ko JY, Kim YK, Kho HS. Salivary flow rate and clinical characteristics of patients with xerostomia according to its aetiology. J Oral Rehabil. 2010;37:185-93.

5- Dawes C. Circadian rhythms in the flow rate and composition of unstimulated and stimulated human submandibular saliva. J Physiol. 1975;44:535-48.

6- Eveson JW. Xerostomia. Periodontology. 2008;48:85-91.

7- Field EA, Fear S, Higham SM, Ireland RS, Rostron J, Willetts $\mathrm{RM}$, et al. Age and medication are significant risk factors for xerostomia in an English population, attending general dental practice. Gerodontology. 2001;18:21-4.

8- Field EA, Longman LP, Bucknall R, Kaye SB, Higham SM, Edgar WM. The establishment of a xerostomia clinic: a prospective study. Br J Oral Maxillofac Surg. 1997;35:96-103.

9- Fox PC, Busch KA, Baum BJ. Subjective reports of xerostomia and objective measures of salivary gland performance. J Am Dent Assoc. 1987;115:581-4.

10- Glazar I, Urek MM, Brumini G, Pezelj-Ribaric S. Oral sensorial complaints, salivary flow rate and mucosal lesions in the institutionalized elderly. J Oral Rehabil. 2010;37:93-9.

11- Guggenheimer J, Moore PA. Xerostomia: etiology, recognition and treatment. J Am Dent Assoc. 2003;134:61-9.

12- Gupta A, Epstein JB, Sroussi H. Hyposalivation in elderly patients. J Can Dent Assoc. 2006;72:841-6.
13- Ikebe K, Matsuda K, Morii K, Wada M, Hazeyama T, Nokubi $T$, et al. Impact of dry mouth and hyposalivation on oral healthrelated quality of life of elderly Japanese. Oral Surg Oral Med Oral Pathol. 2007; 103:216-21.

14- Janket SJ, Jones J, Rich S, Miller D, Wehker CJ, Van Dyke TE, et al. The effects of xerogenic medications on oral mucosa among the veterans dental study participants. Oral Surg Oral Med Oral Pathol Oral Radiol Endod. 2007;103:223-30.

15- Locker D. Subjective reports of oral dryness in an older adult population. Community Dent Oral Epidemiol. 1993;2:165-8.

16- Longman LP, McCracken CF, Higham SM, Field EA. The clinical assessment of oral dryness is a significant predictor of salivary gland hypofunction. Oral Dis. 2000;6:366-70.

17- Napeñas JJ, Brennan MT, Fox PC. Diagnosis and treatment of xerostomia (dry mouth). Odontology. 2009;97:76-83.

18- Navazesh M, Christensen C, Brightman V. Clinical criteria for the diagnosis of salivary gland hypofunction. J Dent Res. 1992; 71:1363-9.

19- Pajukoski H, Meurman JH, Halonen P, Sulkava R. Prevalence of subjective dry mouth and burning mouth in hospitalized elderly patients and outpatients in relation to saliva, medication, and systemic diseases. Oral Surg Oral Med Oral Pathol Oral Radiol Endod. 2001;92:641-9.

20- Shu KI, Lee JY, Chung JW, Lim YK, Kho HS. Relationship between salivary flow rate and clinical symptoms and behaviours in patients with dry mouth. J Oral Rehabil. 2007;34:739-44.

21- Sreebny LM, Valdini A. Xerostomia. A neglected symptom. Arch Intern Med. 1987;147:1333-7.

22- Sreebny LM, Valdini A. Xerostomia. Part I: Relationship to other oral symptoms and salivary gland hypofunction. Oral Surg Oral Med Oral Phatol. 1988;66:451-8.

23- Thelin WR, Brennan MT, Lockhart PB, Singh MI, Fox PC, Papas AS, et al. The oral mucosa as a therapeutic target for xerostomia. Oral Dis. 2008; 14:683-9.

24- Thomson WM. Issue in the epidemiological investigation of dry mouth. Gerodontology. 2005;22:65-76.

25- Torres SR, Peixoto CB, Caldas DM, Akiti T, Barreiros MGC, Uzeda $\mathrm{M}$, et al. A prospective randomized trial to reduce oral Candida spp. colonization in patients with hyposalivation. Braz Oral Res. 2007;21:182-7.

26- Triantos D. Intra-oral findings and general health conditions among institutionalized and non-institutionalized elderly in Greece. J Oral Phatol Med. 2005;34:577-82.

27- Turner M, Jahangiri L, Ship JA. Hyposalivation, xerostomia and the complete denture. J Am Dent Assoc. 2008;139:146-50. 28- Van Steenberghe D, Van Den Eynde E, Jacobs R, Quirynen $M$. Effect of a lactoperoxidase containing toothpaste in radiationinduced xerostomia. Int Dent J. 1994;44:133-8.

29- Von Bültzingslöwen I, Sollecito TP, Fox PC, Daniels T, Jonsson $\mathrm{R}$, Lockhart PB, et al. Salivary dysfunction associated with systemic diseases: systematic review and clinical management recommendations. Oral Surg Oral Med Oral Pathol Oral Radiol Endod. 2007;103:S57e1-15. 